\section{CHIA (Salvia hispanica L.) OIL STABILITY: STUDY OF THE EFFECT OF NATURAL}

\section{ANTIOXIDANTS}

Romina M. Bodoira ${ }^{a}$, María C. Penci ${ }^{\text {bc }}$, Pablo D. Ribotta ${ }^{\text {bc }}$ and Marcela L. Martínez ${ }^{\text {ac }}$

a Instituto Multidisciplinario de Biología Vegetal (IMBIV, CONICET-UNC), Av. Vélez Sarsfield 1611,

Córdoba Argentina.

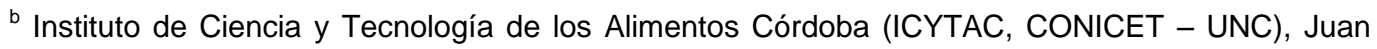
Filloy S/N, Córdoba, Argentina.

${ }^{\mathrm{c}}$ Instituto de Ciencia y Tecnología de los Alimentos (ICTA - FCEFyN - UNC). Av. Vélez Sarsfield 1611, Córdoba Argentina.

${ }^{*}$ Corresponding author: María Cecilia Penci

Email: cpenci@gmail.com

Romina Mariana Bodoira email: rominabodoira@hotmail.com

Marcela Lilian Martínez email: marcelamartinez78@hotmail.com

María Cecilia Penci email: cpenci@gmail.com

Pablo Daniel Ribotta email: pribotta@agro.unc.edu 


\section{ABSTRACT}

The chia seed (Salvia hispanica L.) is globally popular and valued for its nutritional and health attributes. Chia oil is mainly composed of triglycerides, in which polyunsaturated fatty acids (PUFAs, linoleic and a-linolenic acids) are found in high amounts. Although it seems evident that such fatty acid composition is favorable from a nutritional point of view, a higher content of linoleic and linolenic acids results in poorer oxidative stability and shorter shelf life of the oil. The aim of this study was to evaluate the combined effects of the storage condition (300 days under fluorescent light - 800 Lux - or in the dark, both at room temperature) with the addition of natural antioxidants (rosemary extract, RE; tocopherol, TOC; ascorbyl palmitate, AP). In the dark, the combined addition of AP and TOC significantly reduced lipid oxidation and improved oil shelf life. Moreover, this combination maintained an acceptable quality of at least up to 300 storage days. Results from this work highlight the influence of illumination condition on chia oil oxidative stability, suggesting that this oil should be stored in containers with light-barrier properties, and probably added to the antioxidants examined in the current study.

KEY-WORDS: chia oil, oxidative stability, natural antioxidant, storage. 


\section{INTRODUCTION}

Chia (Salvia hispanica L.) is an annual herbaceous plant that belongs to the Lamiaceae family, which is native from southern Mexico and northern Guatemala. Chia seed contains about $0.32 \mathrm{~g}$ oil $/ \mathrm{g}$ seed; $0.28 \mathrm{~g}$ fiber $/ \mathrm{g}$ seed, $0.21 \mathrm{~g}$ protein $/ \mathrm{g}$ seed and $0.05 \mathrm{~g}$ ash $/ \mathrm{g}$ seed, and chia oil contains the highest proportion of $\alpha$-linolenic acid $(0.6 \mathrm{~g} / \mathrm{g}$ oil) from any known vegetable source (Ayerza \& Coates 2004). The antioxidant capacity of this oil is relatively low because the phenolic compounds present in the seed are mostly hydrophilic in nature (Da Silva Marineli et al. 2014). Polyunsaturated fatty acids (PUFA) play a major role in the prevention and treatment of non-communicable diseases (NCDs), also known as chronic diseases, such as: hypertension, coronary artery disease, diabetes and cancer (Fereidoon 2009; Poudyal et al. 2012). Although it seems clear that such fatty acid composition is favorable from a nutritional point of view, a higher content of PUFAs results in poorer oxidative stability and shorter shelf life of the oil. When PUFAs are exposed to environmental factors such as air, light and temperature, oxidation reactions produce undesirable flavors, rancid odors, discoloration and other forms of spoilage. Natural or synthetic antioxidants can increase the shelf life of food products by retarding lipid oxidation through different action mechanisms. The synthetic antioxidants of the food industry, such as butylated hydroxyanisole (BHA), butylated hydroxytoluene (BHT) and tertbutyl hydroquinone (TBHQ), have widespread use as food additives; yet, their effects on human health and metabolic routes are being questioned (Shahidi \& Zhong 2005; lqbal \& Bhanger 2007). As a result, there is a great interest in obtaining and using antioxidants from natural sources, such as simple phenols, phenolic acids, carotenoids, anthocyanins, flavonoids, vitamins and spice extracts (Maestri et al 2006). Among these, rosemary extract (Rosmarinus officinalis $L$ ) has been evaluated in many studies on different lipid matrices (Hras et al 2000; Erkan et al 2008; Ixtaina et al 2012; Martinez et al 2013 a Martinez et al 
2013 ; Chen et al 2014). This is a GRAS additive and its major active antioxidant component is carnosic acid (Terpinc et al 2009). Ascorbic acid has strong reducing properties due to the presence of the enediol group. The tocopherols abound naturally in unrefined vegetable oil and have been extensively tested. Numerous studies have evaluated antioxidant effectiveness in different lipid matrices by accelerated oxidation tests; however, work carried out under real storage conditions is scarce (Gómez Alonso et al 2007; Let et al 2007; Olmedo et al 2008; 2009 Arcoleo et al 2009; Ixtaina et al 2012; Martinez et al $\left.2013^{\mathrm{a}}\right)$.

This work aimed at evaluating the effectiveness of natural antioxidants alone and/or in combination during ten-month storage in the dark and at room temperature in the oxidative stability of chia oil obtained by cold pressing.

\section{MATERIALS AND METHODS}

\subsection{Materials}

Chia seeds were obtained from commercial plantations in the province of Salta. Chia oil extraction was carried out in a single step with a Komet screw press, pilot plant scale type (Model CA 59 G, IBG Monforts, Germany). The moisture content of the seeds was adjusted to $0.11 \mathrm{~g} / \mathrm{g}$ dry basis, the pressing temperature was $30^{\circ} \mathrm{C}$, the screw speed was $20 \mathrm{rpm}$ and the restriction die was $6 \mathrm{~mm}$ (Martínez et al 2012). The oil obtained was filtered through a filter press and stored until use in amber glass bottles at $-20{ }^{\circ} \mathrm{C}$ under nitrogen atmosphere.

Natural mixed tocopherols (GUARDIAN ${ }^{\mathrm{TM}}$ TOCO 70 IP A), rosemary extract (GUARDIAN ${ }^{\mathrm{TM}}$ 12, fat soluble), ascorbyl palmitate (GRINDOX ${ }^{\mathrm{TM}} 562$ ), citric acid (GRINDOX ${ }^{\mathrm{TM}} 373$ ) and a commercial mixture of ascorbyl palmitate (10\%) and tocopherols (10\%) (GRINDOX ${ }^{\mathrm{TM}} 497$ ) 
were obtained from Danisco (Copenhagen, Germany). The content of the main rosemary antioxidative components (carnosic acid) was $1 \%$ and the relative percentage of tocopherol isomers was analysed by HPLC (purity 70\%: $\alpha=8,8 \%, \beta=1,55 \%, \gamma=61,82 \%$ and $\delta=$ 27,82\%). Tertbutyl hydroquinone (TBHQ), a synthetic antioxidant, was used as a positive control due to its known ability to stabilize edible oils and consequent wide use in the food industry.

\subsection{Methods}

\subsubsection{Total seed oil content}

Three samples (10 $\mathrm{g}$ each) of dry chia seeds were used to determine total oil content in accordance with AOCS official method Ba 3-38 (AOCS, 2009).

\subsubsection{Oil analysis}

Acidity index $(\mathrm{Al})$, peroxide $(\mathrm{PV}), \mathrm{K}_{232}$ (conjugated dienes, $\mathrm{CD}$ ) and $\mathrm{K}_{270}$ (conjugated trienes, CT) values were evaluated using standard AOCS (2009) methods. Chlorophyll and carotenoid content was determined at 670 and $470 \mathrm{~nm}$, respectively, in cyclohexane via specific extinction values using the method of Mínguez- Mosquera et al. (1991).

The oxidative stability (OSI) was measured following the Rancimat (Metrohm, Switzerland) method (Cd 12b-92 AOCS, 2009) by using $3 \mathrm{~g}$ oil aliquots. Airflow rate was set at $20 \mathrm{~L} / \mathrm{h}$ and temperature of the heating block was maintained at $100{ }^{\circ} \mathrm{C}$. Results corresponded to the break points in the plotted curves and were expressed as induction time (IT) in hours.

To evaluate radical scavenging capacity (RSC), $100 \mathrm{mg}$ of chia oil in $1 \mathrm{~mL}$ toluene was vortexed (20 s, ambient temperature) with $3.9 \mathrm{~mL}$ toluene solution of the free stable DPPH (2,2-diphenyl-1-picrylhydrazyl) radical (DPPH) at a concentration of $10^{-4} \mathrm{~mol} / \mathrm{L}$ according to Martinez et al (2008). Against a blank of pure toluene, the absorption at $515 \mathrm{~nm}$ was 
measured in $1 \mathrm{~cm}$ quartz cells using an UV-visible spectrophotometer (Perkin-Elmer Lambda 25, Shelton, CT, USA). RSC toward DPPH was estimated by mean of the following equation:

$\mathrm{DPPH}=\{1-[($ Absorbance of control - Absorbance of test sample $) /$ Absorbance of control] $] \times 100$

Where $\mathrm{DPPH}$ expresses the amount of the radical that remains in the medium after the antioxidants in the oil sample are depleted (Espín et al. 2000). RSC was expressed as IC50, reflecting the depletion of the free radical to 50\%. A lower IC50 value indicates higher antiradical activity.

For fatty acid (FA) composition determinations, $0.5 \mathrm{~g}$ of oil was subjected to alkaline saponification by reflux (45 min) using $30 \mathrm{~mL} 1 \mathrm{~N} \mathrm{KOH}$ in methanol. Unsaponificable matter was extracted with $n$-hexane $(3 \times 30 \mathrm{~mL})$. FA were converted to methylesters (FAME) by reflux (45 min) using $50 \mathrm{~mL} 1 \mathrm{~N} \mathrm{H}_{2} \mathrm{SO}_{4}$ in methanol and analysed by gas chromatography (GC) (Perkin-Elmer, Shelton, CT, USA) using a fused silica capillary column (30 m x 0.25 mm i.d.x 0.25 Im film thickness) CP Wax 52 CB (Varian, Walnut Creek, CA, USA); carrier gas $\mathrm{N}_{2}$ at $1 \mathrm{~mL} / \mathrm{min}$; split ratio $100: 1$; column temperature programmed from $180{ }^{\circ} \mathrm{C}$ to 240 ${ }^{\circ} \mathrm{C}(10 \mathrm{~min})$ at $4{ }^{\circ} \mathrm{C} / \mathrm{min}$; injector and detector temperatures at $250{ }^{\circ} \mathrm{C}$, FID. The identification of FAME was carried out by comparison of their retention times with those of reference compounds (Sigma-Aldrich, St. Louis, MO, USA) (Martinez et al. 2013 a). lodine value (IV) was calculated from fatty acid percentages (Torres \& Maestri, 2006) by using the formula:

IV $=(\%$ Palmitoleic acid $\times 1.001)+(\%$ Oleic acid $\times 0.899)+(\%$ Linoleic acid $\times 1.814)$ 
164 The relationship between monounsaturated fatty acids (MUFA) and polyunsaturated fatty acids (PUFA) was also calculated: acid)

Tocopherols were analyzed by HPLC (Perkin-Elmer, Shelton, CT, USA) according to the procedure of Lazzez et al. (2008) with some modifications. Samples of $1 \mathrm{~g}$ oil were placed into $10 \mathrm{~mL}$ volumetric flasks. A quantity of $\mathrm{n}$-hexane was added, swirling to dissolve the was injected onto a Supelcosil LC-NH2-NP column $(25 \mathrm{~cm}$ x $4.6 \mathrm{~mm}$, Supelco, Bellefonte, PA, USA). The mobile phase was n-hexane/ethyl acetate $(70 / 30 \mathrm{v} / \mathrm{v})$ with a flow rate of 1 $\mathrm{mL} / \mathrm{min}$. UV detection at $295 \mathrm{~nm}$ was performed. Individual tocopherols were identified by comparison of their retention times with those of authentic standards (CN Biomedicals, Costa Mesa, CA). Individual tocopherols were quantified by the external standard method. individual of twenty standard solutions with known concentrations. The concentration was expressed as $\mathrm{mg}$ tocopherol / $\mathrm{kg}$ of oil.

181 The total phenol content (TPC) in oil was determined by the Folin-Ciocalteau method according to Torres et al (2009). Briefly, phenolic compounds were analysed in $20 \mathrm{~g}$ aliquots of oil. They were dissolved in $10 \mathrm{~mL}$ of $\mathrm{n}$-hexane and extracted three times with $12.5 \mathrm{~mL}$ of methanol/water $(60: 40 \mathrm{v} / \mathrm{v})$ by stirring over a magnetic plate for $15 \mathrm{~min}$. The pooled extracts were washed twice with $10 \mathrm{~mL}$ of $\mathrm{n}$-hexane, and solvents were removed in a rotating evaporator (Buchi, Flawil, Switzerland) at $30^{\circ} \mathrm{C}$ under vacuum. To 
a suitable dilution of the extracts, Folin-Ciocalteu reagent (Fluka, Buchs, Switzerland) was added and the absorbance values of the solutions at $725 \mathrm{~nm}$ (total phenols) were measured. Total phenol content is given as $\mathrm{mg}$ gallic acid $/ \mathrm{kg}$ oil. In the case of $\sigma$-diphenols, concentration was calculated from the reaction with $\mathrm{Na}_{2} \mathrm{MoO}_{4} \cdot 2 \mathrm{H}_{2} \mathrm{O}$ and reading at $350 \mathrm{~nm}$ (Gutfinger 1981) expressed as $\mathrm{mg}$ caffeic acid/kg oil

Squalene determinations were done from $200 \mathrm{mg}$ oil aliquots according the procedure of Maestri et al. (2015). The unsaponifiable fractions in oil were determinate according Martinez et al. 2006. An aliquot of oil (1g) was saponificated by reflux $(45 \mathrm{~min}, 20 \mathrm{~mL} \mathrm{KOH}$ in methanol $1 \mathrm{M})$ and then extracted with $\mathrm{n}$-hexane $(3 \times 30 \mathrm{~mL})$. Preparative TLC plates $(0.5$ $\mathrm{mm}$ silica gel; Merck, Darmstadt, Germany) were used to separate fractions (toluene/acetone $(95: 5, \mathrm{vol} / \mathrm{vol})$. Sterols and methylsterols were run without further treatment using a VF-5ms (Varian, Walnut Creek, CA) capillary column $(30 \mathrm{~m} \times 0.25 \mathrm{~mm}$ i.d.) coated with a $0.25 \mu \mathrm{m}$ layer of $5 \%$ phenyl, $95 \%$ polydimethylsiloxane; carrier gas N2 at $1 \mathrm{~mL} / \mathrm{min} 1$; column temperature programmed from $240^{\circ} \mathrm{C}(1 \mathrm{~min})$ to $290^{\circ} \mathrm{C}$ at $2^{\circ} \mathrm{C}$ min -1 ; injector and detector temperatures $300^{\circ} \mathrm{C}$; FID. GC-MS used an HP 5 (Hewlett-Packard, Palo Alto, CA) fusedsilica capillary column (30 $\mathrm{m} \times 0.25 \mathrm{~mm}$ i.d.) coated with a $0.25 \mu \mathrm{m}$ layer of $5 \%$ phenyl methyl siloxane, and helium (flow rate $1 \mathrm{~mL} / \mathrm{min}$ ) as carrier gas. The column, injector, and detector temperatures were as for GC analysis. Sterols and methylsterols were identified by comparison of the mass spectral data with those of authentic reference compounds. Hydrocarbons were analyzed by GC and GC-MS. Briefly, hydrocarbons purified by TLC as described above were analyzed by GC using a VF-5ms capillary column. The column temperature was programmed from 70 to $300^{\circ} \mathrm{C}$ at $4^{\circ} \mathrm{C}$ min1, injector and detector temperatures $320^{\circ} \mathrm{C}$, carrier gas $\mathrm{N} 2$ at $1 \mathrm{~mL} / \mathrm{min}$, FID. GC-MS used an HP 5 capillary column and helium (flow rate $1 \mathrm{~mL} / \mathrm{min}$ ) as carrier gas. The column, injector, and detector temperatures were as for GC analysis. Hydrocarbons were identified 
by their retention times and comparison of the mass spectral data with those of authentic reference compounds.

\subsubsection{Rancimat analysis}

Rosemary extracts (RE), tocopherols (TOC), ascorbyl palmitate (AP), citric acid (CA) and blends were added separately to chia oil aliquots at different concentrations. The additives were dissolved in oil by using a shaker 5 min (Martinez et al 2013 a). Tocopherols were in range of 50 to $800 \mathrm{mg} / \mathrm{kg}$; rosemary extract ranged from 1000 to $16000 \mathrm{mg} / \mathrm{kg}$; ascorbyl palmitate from 50 to $700 \mathrm{mg} / \mathrm{kg}$; citric acid $100 \mathrm{mg} / \mathrm{kg}$ and TBHQ 100 and $200 \mathrm{mg} / \mathrm{kg}$. Several combinations were evaluated: ascorbyl palmitate and tocopherols $(50-700 \mathrm{mg} / \mathrm{kg})$, rosemary extract $(8000 \mathrm{mg} / \mathrm{kg})$ and citric acid $(100 \mathrm{mg} / \mathrm{kg})$, rosemary extract $(8000 \mathrm{mg} / \mathrm{kg})$ and ascorbyl palmitate $(200 \mathrm{mg} / \mathrm{kg})$, rosemary extract $(8000 \mathrm{mg} / \mathrm{kg})$ and tocopherols (200 $\mathrm{mg} / \mathrm{kg}$ ). Oil oxidative stability was evaluated by the Rancimat method, using $3 \mathrm{~g}$ of oil sample warmed at $100{ }^{\circ} \mathrm{C}$ with an air flow of $20 \mathrm{~L} / \mathrm{h}$. Oil stability was expressed in terms of induction time (IT) (h) and the effectiveness of all tested antioxidants and their blends was expressed as the protection factor (PF):

$$
\begin{array}{r}
\mathrm{PF}: \underline{\mathrm{IT}} \underline{\underline{\mathrm{ant}}} \\
\mathrm{IT}_{0}
\end{array}
$$

where $\mathrm{IT}_{\text {ant }}$ is the induction time of the samples treated with antioxidant, and $\mathrm{IT}_{0}$ is the induction time of the control system (without antioxidant). 
Upon combining two antioxidants, the resulting IT were used for each concentration to calculate synergism between antioxidants using the equation proposed by Bishov et al. 237 (1977).

where $\mathrm{IT}_{1}$ and $\mathrm{IT}_{2}$ are the induction time of the individual antioxidants, $\mathrm{I} \mathrm{T}_{\text {blend }}$ is the induction time of the mixture of antioxidant 1 and 2 in the same concentration as that alone and $I T_{0}$ is the induction time of the control system (without antioxidant).

\subsubsection{Experimental design for storage stability test}

Antioxidants (RE, AP, TBHQ, TOC, CA) or their mixtures were added to oil samples selected on the basis of Rancimat analyses, and taking into account Argentine Food Code and Codex Alimentarius standards. Briefly, the additives (RE, AP, TBHQ, TOC, CA) were dissolved in $50 \mathrm{~mL}$-oil aliquots by using a shaker (approximately $5 \mathrm{~min}$ ) until a homogeneous oil was achieved. The mixtures (oil plus additive) were transferred separately to transparent glass bottles $(250 \mathrm{~mL}$ ) each containing $200 \mathrm{~mL}$ chia oil. The bottled oils (final volume $250 \mathrm{~mL}$ ) were mixed thoroughly and then placed in a thermostated chamber at $25 \pm$ $1^{\circ} \mathrm{C}$ kept in the dark by wrapping each bottle with an aluminum foil. For each treatment three sets of bottled oils were prepared. For control treatments, oil samples without added antioxidants were used, three of them in the dark (OC) and three without aluminum foil to evaluate effect of photooxidation on chia oil (LC). Bottled oils were stored for ten months under illumination (800 Lux). Every fifteen days, each individual oil sample was withdrawn from the chamber for scheduled analysis. This is a typical dynamic storage assay, 
compared with static storage assay (Ixtaina et al. 2012). In dynamic assays the head space volume increases over time. Acidity $(A)$, peroxide value $(P V), K_{232}$ and $K_{270}$ values were evaluated (AOCS 2009) every fifteen days in each treatment and control. Additionally, with the aim of analyzing possible changes in the characteristic profile of oil, the following determinations were performed on controls (LC and DC) at 0, 165 and 300 days of storage: fatty acid (FA) composition and lodine value, pigments, quantification of tocopherols and radical scavenging capacity (DPPH).

\subsubsection{Statistical analysis}

Statistical differences among treatments were estimated from ANOVA test at the $5 \%$ level $(P<0.05)$ of significance, for all parameters evaluated. Whenever ANOVA indicated a significant difference, a pair wise comparison of mean by least significant difference (Fisher LSD) was carried out.

\section{RESULTS AND DISCUSSION}

\subsection{Chia oil analysis}

Table 1 shows results from chia oil analysis. Acidity (A), peroxide value, conjugated dienes and trienes values (K232 and K270) are similar to those observed in cold-pressed chia oil (Martínez et al. 2012), much lower than the maximum values established by the Codex Alimentarius (2001) for non-refined oils, indicating that the oil extraction method employed did not affect adversely those indicators of hydrolytic and oxidative rancidity. Linolenic acid is the major fatty acid $(61.8 \mathrm{~g} / 100 \mathrm{~g}$ oil) followed by linoleic $(20.1 \mathrm{~g} / 100 \mathrm{~g}$ oil $)$ and oleic $(7.18$ $\mathrm{g} / 100 \mathrm{~g}$ oil) acids. Such composition leads to high unsaturation degree (iodine value, 212). This fact, together with a relatively low tocopherol and phenolic compound concentration , accounts for the low oxidative stability of chia oil (<3.04 h). According to Wong (1995), 
vegetable oils are susceptible to photooxidation during storage under light, especially when photosensitizers, such as chlorophylls, are present. Although chia oil has very low chlorophyll content $(4.66 \mathrm{mg} / \mathrm{kg}$ oil), such concentration may be sufficient to induce photochemical oxidation (Suzuki et al. 1984; Martinez et al. 2013a).

Regarding carotenoid pigments, Warner and Frankel (1987) have shown that, in soybean oil, the presence of $\beta$-carotene at concentrations between 5 and $20 \mathrm{mg} / \mathrm{kg}$ oil has a protective effect against oxidative damage induced by light. Considering the fatty acid composition of chia oil, it can be assumed that carotenoid content $(5.41 \mathrm{mg} / \mathrm{kg}$ oil) is not enough to provide protection against photooxidative degradation.

The unsaponifiable fraction analysis shown that sterols were represented by $\beta$-sitosterol $(60$ $\mathrm{mg} / 100 \mathrm{mg})$, 4-6-cholestadien-3ß-ol (30 mg/100 mg) and campesterol $(9,7 \mathrm{mg} / 100 \mathrm{mg})$, the triterpene alcohols and methylsterols were not detected The hydrocarbon fraction was represented mostly by alkanes, the main were octadecane $(36,42 \mathrm{mg} / 100 \mathrm{mg})$, hexadecane $(29,25 \mathrm{mg} / 100 \mathrm{mg})$, docosane $(16,33 \mathrm{mg} / 100 \mathrm{mg})$ tetradecane $(7,96 \mathrm{mg} / 100 \mathrm{mg})$ and nonadecane $(2,68 \mathrm{mg} / 100 \mathrm{mg})$. Regarding squalene, since there are not previous studies in chia oil, it was analyzed but no significant levels of this hydrocarbon were detected.

\subsection{Natural and synthetic antioxidant performance on chia oil}

In order to evaluate the antioxidant efficiency of natural and synthetic substances (individual or in combination) in chia oil, oxidative stability (Rancimat test) was studied under different conditions. Table 2 shows a summary of antioxidant conditions for chia oil and their protection factors (PF). Considering RE, significant differences can be found ( $p \leq 0.05$ ) between PF of all concentrations tested, but from 10000 ( $\mathrm{mg} / \mathrm{kg}$ oil) a marked decrease is evidenced in the solubility of the extract in oil (turbidity). In addition to this technological drawback, the increase in oxidative stability was not proportional to the increase in the 
concentration of ER, hence we used 8000 (mg/kg oil) of RE. A similar behavior was reported when RE was incorporated to walnut and almond oils (Martinez et al. 2013 ${ }^{\mathrm{a}}$, Martinez et al. $2013^{\mathrm{b}}$ ). Tocopherols showed the lowest antioxidant performance (PF 1.39, $800 \mathrm{mg} / \mathrm{kg}$ oil). For PA, the highest FP was achieved at $800 \mathrm{mg} / \mathrm{kg}$ oil; however, the maximum level has been set to be $200 \mathrm{mg} / \mathrm{kg}$ oil (Codex Alimentarius). At this concentration, PF was $3.55 \pm 0.08$. When RE was combined with CA $100(\mathrm{mg} / \mathrm{kg}$ oil), the blend showed a significant additional protective effect $(p \leq 0.05)$ compared to that of RE alone. When achieved, synergism was relatively low despite being positive (17.25\%). Some authors reported that the combination of PA and TOC could be positive for some oils (Marinova \& Yanishlieva 1990). In this work an equal part blend of each antioxidant was evaluated. For $250 \mathrm{mg} / \mathrm{kg}$ oil TOC and $250 \mathrm{mg} / \mathrm{kg}$ oil PA, the maximum PF $(9.49 \pm 0.05)$ was achieved. The synergism effect varied from 141 per cent $(300 \mathrm{mg} / \mathrm{kg}$ oil TOC +300 $\mathrm{mg} / \mathrm{kg}$ oil PA) to 42 per cent (400 mg/kg oil TOC + $400 \mathrm{mg} / \mathrm{kg}$ oil PA). In order to compare natural and synthetic antioxidants, TBHQ was employed at 100 and $200 \mathrm{mg} / \mathrm{kg}$ oil in chia oil. PF were $3.79 \pm 0.07$ and $6.64 \pm 0.01$ respectively, showing that the antioxidant capacity of synthetic additives could be higher than that of natural antioxidants for chia oil.

\subsection{Storage stability test of chia oil}

Considering the results obtained from the study of antioxidant performance in chia oil and regulations in force on the level of additives, Table 3 shows concentration of each antioxidant and storage condition. The oxidative stability of chia oil stored in the dark without adding any antioxidant shows a similar oxidation rate than that stored under light. Carotenoids do not show a statistically significant difference between both lighting conditions; yet, chlorophylls show a decrease of $80 \%$ and $63 \%$ under light and dark conditions, respectively. The antioxidant activity of this edible oil decreased at 300 days of 
storage in both lighting conditions. This could be attributed to the fact that tocopherol content in chia oil decreased by approximately $30 \%$. The relative proportion of the different fatty acids was not significantly affected during storage. Particularly, acidity did not differ significantly $(p \leq 0.05)$ between treatments, showing no significant increase in time. Considering that the maximum allowed for this parameter in chia oil is around $1 \mathrm{~g}$ oleic acid $/ 100 \mathrm{~g}$ oil, in this test, at 165 days of storage, CL condition presented a 0.22 value. This evidences that chia oil is stable against the hydrolytic degradation of glycerides, even under exposure to light. Figure 2 shows that the combination of ascorbyl palmitate (AP) and tocopherols (TOC) at $200 \mathrm{mg} / \mathrm{kg}$ oil each is more effective in the stabilization of chia oil than the addition of TBHQ at $200 \mathrm{mg} / \mathrm{kg}$ oil stored in the dark $\left(0.66\right.$ and 2.35 meq $\mathrm{O}_{2} / \mathrm{kg}$ oil at 300 days of storage, respectively). However, the addition of ascorbyl palmitate (AP) at 200 $\mathrm{mg} / \mathrm{kg}$ oil, tocopherols (TOC) at $200 \mathrm{mg} / \mathrm{kg}$ oil and rosemary extract (RE) at $8000 \mathrm{mg} / \mathrm{kg}$ oil did not show good antioxidant capacity, exceeding 15 meq $\mathrm{O}_{2} / \mathrm{kg}$ oil (Codex Alimentarius, 2001) from approximately 135-150 days of storage (Figure 1). Although found in static tests, similar trends were reported by Ixtaina et al. 2012 for rosemary extract and for the addition of tocopherol in the preservation of chia oil. It should be noted that light exerts a significant effect on the generation of primary oxidation products, accelerating photooxidation probably due to the presence of photosensitizers such as chlorophylls (Wong, 1995; Frankel, 2005) in sufficient quantity to promote photochemical production of singlet oxygen (Suzuki et al. 1984). Regarding K232 and K270, parameters show the same trend as that found in PV. In addition, pigment content in chia oil decreased significantly at 165 days of storage.

\section{CONCLUSIONS}

The nutritional benefits gained by consuming chia oil are mainly ascribed to the high content of $\omega 3$ and $\omega 6$ fatty acids; yet, they also show a technological disadvantage in terms of product stability. Although chia oil contents naturally antioxidant substances to prevent 
oxidation, when exposed to environmental factors such as light and the oxygen, its chemical quality could be altered. In response to this, it was found that the protective effect of the combination of natural antioxidants PA and TOC (50:50) was more marked than that achieved with TBHQ, one of the most widely used synthetic antioxidants. This result represents an interesting alternative for these unconventional oils from crops being reexamined in the country and in the continent as a novel alternative to the oil industry.

\section{ACKNOWLEDGEMENTS}

The authors thank SECyT from Universidad Nacional de Córdoba, Consejo Nacional de Investigaciones Científicas y Tecnológicas (CONICET) and Fund for Scientific Research and Technology (FONCyT) for the cooperation received to carry out this work.

\section{REFERENCES}

AOCS. (2009). Official Methods and Recommended Practices of the American Oil Chemists' Society (5th ed.). Champaign, II, USA: AOCS Press.

Arcoleo, G., Indovina, M.C., Varvaro, G., Lanza, C.M. \& Mazzaglia, A. (2009). Improving olive oil shelf life with lemon essecial oil. Chemical Engineering Transactions 17: 849-854.

Ayerza, R. \& Coates, W. (2004). Composition of chia (Salvia hispanica L.), grown in six tropical and subtropical ecosystems of South America. Tropical Science 44 (3): 131-135.

Ayerza, R. \& Coates, W. (2011). Protein content, oil content and fatty acid profiles as potential criteria to determine the origin commercially grown chia (Salvia hispanica L.). Industrial Crops and Products 34: 1366-1371. 
388 Bishov, S. J., Masuoka, Y. \& Kapsalis, J. G. (1977). Antioxidant effect of spices, herbs and

protein hydrolyzates in freeze-dried model systems: synergistic action with synthetic phenolic antioxidants. Journal of Food Processing and Preservation 1: 153-166.

Chen, X., Zhang, Y., Zu, Y., Yang, L., Lu, Q. \& Wang, W. (2014). Antioxidant effects of rosemary extracts on sunflower oil compared with synthetic antioxidants. International Journal of Food Science and Technology 49: 385-391.

Código Alimentario Argentino. Capítulo VII: Alimentos grasos y aceites comestibles. Artículo 523bis - (Res 2012, 19.10.84) yCapítulo XVII: Alimentos de régimen o dietéticos. Artículo 1381 bis (Resolución Conjunta SPRel N 76/2009 y SAGPyA N³91/2009).

Da Silva Marineli, R., Aguiar Moraes, E., Alves Lenquiste, S., Teixeira Godoy, A., 400 Nogueira Eberlin, M. \& Maróstica, M.R. (2014). Chemical characterization and antioxidant 401 potential of Chilean chia seeds and oil (Salvia hispanica L.). Food Science and Technology 402 $59: 1304-1310$.

Erkan, N., Ayranci, G. \& Ayranci, E. (2008). Antioxidant activities of Rosemary (Rosmarinus Officinalis L.) extract, blackseed (Nigella sativa L.) essencial oil, carnosic acid, rosmarinic acid and sesamol. Food Chemistry 110: 76-82. 
412 Ferereidoon, S. (2009). Omega-3 en alimentos. Un análisis sobre la incorporación de 413 ácidos grasos Omega-3 en los alimentos y su significado para la salud. Aceites \& Grasas 414 76: 476-479.

Frankel, E.N. (2005). Lipid oxidation. Ed. Barnes \& Associates, Bridgwater, England.

417 Gómez-Alonso, S., Mancebo-Campos, V., Salvador, M.D. \& Fregapane, G. (2007).

418 Evolution of major and minor components and oxidation indices of virgin olive oil during 21

419 month storage at room temperature. Food Chemistry 100: 36-42.

421 Gutfinger, T. (1981). Polyphenols in olive oils. Journal of the American Oil Chemists' 422 Society 58: 966-968.

Hras, A.R., Hadolin, M., Knez, Z. \& Bauman, D. (2000). Comparison of antioxidative and synergistic effects of rosemary extract with a-tocopherol, ascorbyl palmitate and citric acid in sunflower oil. Food Chemistry 71: 229-233.

Iqbal, S. \& Bhanger, M.I. (2007). Stabilization of sunflower oil by galic extract during accelerated storage. Food Chemistry 100: 246-254.

Ixtaina, V.Y., Martinez, M. Spotorno, V., Mateo, C.M., Maestri, D.M., Diehl, B.W.K., 432 Nolasco, S.M. \& Tomás, M.C. (2011). Characterization of chia seed oils obtained by pressing and solvent extraction. Journal of Food Composition and Analysis 24: 166-174. 
Ixtaina , V. Y., Nolasco, S.M. \& Tomás , S.M. (2012). Oxidative stability of chia (Salvia hispanica L.) seed oil: effect of antioxidants and storage conditions. Journal of the American Oil Chemists' Society 89: 1077-1090.

Lazzez, A., Perri, E., Caravita, M. A., Khlif, M., Cossentini, M. (2008). Influence of olive maturity stage and geographical origin on some minor components in virgin olive oil of the Chemlali variety. Journal of Agricultural and Food Chemistry. 53, 982-988.

Let, M.B., Jacobsen, C. \& Meyer, A.S. (2007). Ascorbyl palmitate, Y-Tocopherol and EDTA affect lipid oxidation in fish oil enriched salad dressing differently. Journal of Agricultural and Food Chemistry 55: 2369-2375.

Maestri, D.M., Nepote, V., Lamarque, A.L., Zygadlo, J.A. (2006). Natural products as antioxidants. En: Phytochemistry: Advances in research (Imperato, F., Ed.), Research Signpost, Trivandrum, Kerala, India. pp: 105-135.

Maestri, D., Martínez, M, Bodoira, R., Rossi, Y, Oviedo, A., Pierantozzi, P, \& Torres, M. (2015). Variability in almond oil chemical traits from traditional cultivars and native genetic resources from Argentina. Food Chemistry 170 (1): 55-61.

Marinova, E.M. \& Yanishlieva, N.V. (1990). Inhibited oxidation of lipids III: on the activity of ascorbyl palmitate during the autoxidation of two types of lipid systems in the presence of $\alpha$ tocopherol. European Journal of Lipid Science and Technology 94: 448-452. 
Martínez, M. L., Marín M.A., Salgado Faller, C.M., Revol, J., Penci, M.C. \& Ribotta P.D.

Con formato: Español (Argentina) (2012). Chia (Salvia hispanica L.) oil extraction: Study of processing parameters. Food Science and Technology 47: 78-82.

Martínez, M.L., Mattea, M.A. \& Maestri, D.M. (2006). Varietal and crop year effects on lipid composition of walnut (Juglans regia) genotypes. Journal of the American Oil Chemists' Society 83: 791-796.

Martinez M.L \& Maestri, D. (2008) Oil chemical variation in walnut (Juglans regia L.) genotypes grown in Argentina. European Journal of Lipid Science and Technology 110: $1183-1189$.

Martínez, M. L., Penci, M.C., Ixtaina, V., Ribotta P.D. \& Maestri, D. (2013)a . Effect of natural and synthetic antioxidants on the oxidative stability of walnut oil under different storage conditions. Food Science and Technology 51: 44-50.

Martínez, M. L., Penci, M.C., Marin, M.A ., Ribotta P.D. \& Maestri, D. (2013) ${ }^{\text {b }}$ Screw press extraction of almond (Prunus dulcis (Miller) D.A. Webb): Oil recovery and oxidative stability. Journal of Food Engineering 119:40-45.

Minguez-Mosquera, M.I., Rejano, L., Gandul, B., Sánchez, A.\& Garrido, J. (1991). Color pigment correlation in virgin olive oil. Journal of the American Oil Chemists' Society 68: 332-336. 
481 Olmedo, R., Nepote, V., Mestrallet, M.G. \& Grosso, N.R. (2008). Effect of the essencial oil 482 addition on the oxidative stability of friend-salted peanuts. International Journal of Food 483 Science and Technology 43: 1935-1944.

Olmedo, R., Asensio, C., Nepote, V., Mestrallet, M.G. \& Grosso, N.R. (2009). Chemical 486 and sensory stability of fried-salted peanuts flavored with oregano essencial oil and olive oil. Journal Science of Food Agriculture 89: 2128-2136.

Poudyal, H. Panchal, S.K., Waanders, J., Ward, L. \& Brown L. (2012). Lipid redistribution by $\alpha$-linolenic acid-rich chia seed inhibits stearoyl-CoA desaturase- 1 and induces cardiac and hepatic protection in diet-induced obese rats. Journal of Nutritional Biochemistry 23: $153-162$

Shahidi, F. \& Zhong, Y. (2005). Antioxidants: regulatory status. In: Bailey's Industrial Oil and

Fat Product (Shahidi, F.). New York: John Wiley \& Sons, Inc. pp: 491-512.

Suzuki, T., Suzuki, Y., Endo, Y. \& Kaneda, T. (1984). Residual amounts of chlorophylls and 498 pheophytins in refined edible oils. Journal of the American Oil Chemists' Society 61: 785499788.

501 Terpinc, P., Bezjak, M. \& Abramovi, H. (2009). A kinetic model for evaluation of the antioxidant activity of several rosemary extracts. Food Chemistry 115: 740-744. 
504 Torres, M.M. \& Maestri, D.M. (2006). The effects of genotype and extraction methods on 505 chemical composition of virgin olive oils from Translasierra Valley (Córdoba, 506 Argentina). Food Chemistry 96: 507-511.

508 Torres, M.M,, Pierantozzi, P. Cáceres, M.E., Labombarda, P., Fontanazza, G. \& Maestri, 509 D.M. (2009). Genetic and chemical assessment of Arbequina olive cultivar grown in 510 Córdoba province, Argentina. Journal of the Science of Food and Agricultural 89: 523-530

512 Warner, K., \& Frankel, E. N. (1987). Effect of $\beta$-carotene on light stability of soybean oil. 513 Journal of the American Oil Chemists' Society 64: 213-218.

515 Wong, D.W.S. (1995). Lipids. In: Food Chemistry: Mechanisms and theory. Ed. Acribia, 